\title{
Comment on: "The Challenge of Maintaining Metabolic Health During a Global Pandemic"
}

\author{
Lino Sérgio Rocha Conceição ${ }^{1,2}$ (1) $\cdot$ Cristiane Vilaça Campos Gomes ${ }^{1,2} \cdot$ Vitor Oliveira Carvalho $^{1}$
}

Published online: 26 June 2020

C) Springer Nature Switzerland AG 2020

\section{Dear Editor,}

The current pandemic of coronavirus disease (COVID-19), caused by the new SARS-CoV-2 virus, has already infected over 5 million people worldwide [1]. Many efforts are being made in order to mitigate and stop the further spread of the virus. Measures of social distancing, screening of suspected cases and isolation of infected patients are some of the main public health policies to control the pandemic. However, a great number of the patients remain asymptomatic, making the identification of new cases even harder.

In a current opinion article, King et al. discussed how to maintain metabolic health during the pandemic [2]. The authors proposed that regular physical activity should be a mainstay of good health. One of the exercise modalities suggested was high-intensity interval training due to the variety of time protocols and the possibility of burning many calories in a short amount of time. However, the benefits of exercise training can go beyond calorie consumption.

According to a previous study, dyspnea accounts for $55 \%$ of the symptoms of patients with COVID-19[3]. However, the time between infection and the onset of dyspnea is 5-13 days [3]. Interestingly, patients with COVID-19 may present pulmonary alterations before the beginning of symptoms. It is possible that dyspnea at rest could be a "late" symptom of pulmonary injury. Assessment of ventilatory efficiency is a useful way to evaluate the presence or severity of heart and/or lung disease. In regular situations, lung ventilation is closely related to the output of carbon

This comment refers to the article available at https://doi. org/10.1007/s40279-020-01295-8.

Lino Sérgio Rocha Conceição

linosergiorocha@gmail.com

1 Department of Physical Federal Therapy, The GREAT Group (GRupo de Estudos Em ATividade fisica), Federal

University of Sergipe (UFS), Aracaju, Sergipe, Brazil

2 Federal University of Sergipe (UFS), Aracaju, Sergipe, Brazil dioxide $\left(\mathrm{CO}_{2}\right)$ output and partial pressure of carbon dioxide $\left(\mathrm{PaCO}_{2}\right)$. Whenever a mismatch occurs in this relationship (i.e., increases in $\mathrm{PaCO}_{2}$ ), the efficiency of gas exchange is reduced, leading to increases in ventilation to compensate for the new levels of $\mathrm{PaCO}_{2}$. Such alterations contribute to the exertional dyspnea found in patients with cardiac and pulmonary disturbances, such as chronic heart failure and chronic obstructive pulmonary disease-COPD) [4].

People that practice regular physical activity and athletes are more likely to rapidly identify ventilatory alterations during training or competitions through their rate of perceived exertion (RPE) (5). Thus, unusual changes in perceived exertion can be, potentially, a sign of early stage COVID-19.

This can be useful in some settings, e.g. the German national soccer league (Bundesliga) that recently restarted. Players that, during training sessions or match play, experience alterations of ventilatory function or report altered RPE should be closely monitored for possible infection, allowing proper testing, isolation and care. Additionally, early identification of COVID-19 allows training sessions, matches and competitions to continue safely. The same reasoning can be applied to non-athletes, in whom any alteration in perceived exertion that cannot be explained by other causes could be associated with an "early" stage of COVID-19. In such cases, proper communication with health care providers should be made to prevent worse consequences of "late" identification.

In the COVID-19 pandemic era paying attention to how our body reacts during exercise can possibly help us to identify and mitigate the virus.

\section{Compliance with Ethical Standards}

Funding No sources of funding were used to assist in the preparation of this letter. 
Conflict of interest Lino Sérgio Rocha Conceição, Cristiane Vilaça Campos Gomes and Vitor Oliveira Carvalho declare that they have no conflicts of interest relevant to the content of this letter.

\section{References}

1. Dong E, Du H, Gardner L. An interactive web-based dashboard to track COVID-19 in real time. Lancet Infect Dis. 2020. https:// doi.org/10.1016/S1473-3099(20)30120-1.

2. King AJ, Burke LM, Halson SL, Hawley JA. The challenge of maintaining metabolic health during a global pandemic. Sports Med. 2020. https://doi.org/10.1007/s40279-020-01295-8.
3. Huang C, Wang Y, Li X, Ren L, Zhao J, Hu Y, et al. Clinical features of patients infected with 2019 novel coronavirus in Wuhan, China. Lancet. 2020;395(10223):497-506.

4. Sun XG, Hansen JE, Garatachea N, Storer TW, Wasserman K. Ventilatory efficiency during exercise in healthy subjects. Am J Respir Crit Care Med. 2002;166(11):1443-8.

5. Schellhorn P, Klingel K, Burgstahler C. Return to sports after COVID-19 infection: do we have to worry about myocarditis? Eur Heart J. 2020. https://doi.org/10.1093/eurheartj/ehaa448. 